\title{
Emojis in public health and how they might be used for hand hygiene and infection prevention and control
}

\author{
Nasim Lotfinejad ${ }^{1,2}$, Reza Assadi ${ }^{3}$, Mohammad Hassan Aelami $^{4}$ and Didier Pittet $^{5^{*}}$
}

\begin{abstract}
Emojis are frequently used picture characters known as possible surrogates for non-verbal aspects of behavior. Considering the ability of emojis to enhance and facilitate communication, there has been a growing interest in studying their effects in scientific and health-related topics over the past few years. Infection prevention and control (IPC) is a field of medicine that is directly associated with specific behaviors. These include hand hygiene, which is the cornerstone of the prevention of healthcare-associated infections, and essential in stemming the spread of antimicrobial resistance. This paper aims to provide an overview of how emojis have been used in the medical and public health literature and proposes their possible use in IPC and hand hygiene to put forth a vision for the future research.

Keywords: Infection prevention and control, Infection control, Emoji, Emoticon, Ideograms, Infection prevention, Hand hygiene, World Health Organization, Healthcare-associated infection, Global health, Behavioral change, Alcohol-based handrub, Hand sanitizer
\end{abstract}

\section{Introduction}

Emojis are new generation of emoticons. These ideograms have evolved beyond facial expressions, and are increasingly used on digital platforms to demonstrate concepts and ideas. As a Japanese word meaning "picture character", emojis were initially created at the end of the twentieth century in order to improve and simplify digital messages $[1,2]$. They are increasingly used as a new language worldwide, conveying nonverbal communication cues and, in the case of the latter, substituting for the face-to-face conditions, and proving to exert a direct effect on readers' moods [3, 4]. Emojis have enabled users from different countries to communicate in a standardized way with single compact characters that circumvent language barriers [5, 6]. The number of existing emojis is increasing each year in a number of categories including smileys and people, animals and nature, food and drinks, activity, travel and places, objects,

\footnotetext{
* Correspondence: Didier.pittet@hcuge.ch

${ }^{5}$ Infection Control Programme and WHO Collaborating Centre on Patient

Safety, University of Geneva Hospitals and Faculty of Medicine, 4 Rue

Gabrielle-Perret-Gentil, 1211 Geneva 14, Switzerland

Full list of author information is available at the end of the article
}

symbols, and flags [1]. These pictographs became so popular that the Oxford dictionary announced the "face with tears of joy" ( emoji as the 2015 word of the year [7]. More than $90 \%$ of the online users employ emojis to communicate complex concepts more effectively while using less words [2].

As technology improves and emojis continue to grow in popularity in the digital world, various studies have been conducted in the past few years regarding the impact of these symbols in scientific fields. However, the use of emojis has not yet been highlighted in the medical literature. These surrogates of nonverbal communication have a direct impact on different social interactions that could facilitate communication among healthcare providers and receivers, thus enhancing public health [8]. This paper primarily focuses on the possible effects of emojis on healthcare systems and outlines important issues for further consideration. The potential roles of these symbols in infection prevention and control (IPC), as a globally recognized essential part of health systems [9], are further described through the example of using emojis to promote hand hygiene.

(C) The Author(s). 2020 Open Access This article is distributed under the terms of the Creative Commons Attribution 4.0 International License (http://creativecommons.org/licenses/by/4.0/), which permits unrestricted use, distribution, and reproduction in any medium, provided you give appropriate credit to the original author(s) and the source, provide a link to the Creative Commons license, and indicate if changes were made. The Creative Commons Public Domain Dedication waiver (http://creativecommons.org/publicdomain/zero/1.0/) applies to the data made available in this article, unless otherwise stated. 


\section{Emojis in healthcare literature}

The ever-evolving medical language, which is globally accepted as medical English, has faced significant changes over time [10]. But despite all the developments that have taken place, language barriers still hinder disseminating knowledge worldwide [11] by preventing sufficient quality of care among patients and healthcare providers who speak different languages and come from different cultures $[12,13]$. Numerous pictographs have been developed to enrich verbal communication and facilitate digital communication by substituting for nonverbal cues [8]. They received so much attention that in 2005, a number of medical emoticons were recommended instead of abbreviations and acronyms used in medicine [14]. Emojis are a step further than emoticons. For example, ":-O" is an emoticon for surprise while " $\because$ " is the emoji with the same meaning. More natural in design, emojis have attracted scientific attention as they are able to transmit emotion, attitude and attention when added to text $[1,15]$. As emojis are easily distributed by users around the world, they enable researchers to conduct studies and surveys across geographical boundaries using this language [6].

Shah et al. [5] suggested benefiting from emojis by adding them in editorial communications and writing manuscripts using emojis as substitutes for words to augment medical literature. However, some disadvantages of using emojis in scientific studies were reported such as lack of standardization in different platforms, variability of meaning over time and according to different cultures, and conveyance of unintended messages. Concerning the infiltration of emojis into scientific literature, it is imperative to evaluate the impact of these symbols in health-related fields in order to harness their potential advantages for appropriate research applications and stave off scientific miscommunication. The impact of narrative health messages and emojis on message processing and attention has been studied by Willoughby and Liu [16]. Their findings demonstrated that using emojis in health messages is reliant on the objectives and content of the message. According to the authors, participants' attention was better when emojis were added to weaker and less interesting health messages. Another study conducted by Siegel et al. [17] on 297 elementary school children revealed that placing "Green Smiley Face" emoticons near plain milk and vegetables increased their desire to purchase healthy products. Lee et al. [18] used emojis as simple, languageindependent, and less time consuming tools for detecting depression after stroke. Based on their results, the sad emoticon showed a high agreement rate with the Diagnostic and Statistical Manual for Major Depression, fourth edition, and the use of emojis was found effective in screening for depression among patients. Marengo et al. [19] developed a 91-item questionnaire with emojis related to personality characteristics in order to assess a language-free instrument for personality. The authors involved a sample of 234 young adults online, and a brief Big-Five personality questionnaire was administered along with the emoji questionnaire to each participant. It was concluded that 36 out of 91 emojis were significantly associated with extraversion, emotional stability and agreeableness. Other studies have been conducted regarding the use of emojis, especially in psychology [20-23]; yet there is only limited data on the effects of these pictographs in other fields of medicine. The latter is mainly due to the availability of many emojis describing emotion and behavior, while only a few emojis are precisely related to health and medical terms.

With the dramatic increase in public awareness about the significant role of the Internet and social media in disseminating health-related data [24], Internet access to medical information has gone far beyond reading sources as we are witnessing more interactive communicational methods being introduced each day [25]. Medical emojis have a great potential to gain popularity on digital platforms as the Internet is an integral part of both healthcare workers' and patients' lives. Currently, attempts are being made to create new emojis related to health issues, such as the medical sign and symptoms [26]. In a recent study, Assadi et al. have designed and evaluated the possibility of using emojis to depict about 80 clinical signs and symptoms according to the 10th revision of the International Statistical Classification of Diseases [27].

\section{Emojis in infection prevention and control}

Implementing IPC programs is recognized as a global health priority, and it is known that failure to achieve an adequate level of IPC harms patients around the world. That points to the necessity of using a full arsenal of tools and technologies to improve IPC interventions globally [28]. In recent times, trends in infectious diseases have become detectable in populations via the Internet and social media; they function as new and available sources of health-related data $[29,30]$. This ability of the Internet and social media was further illustrated in a study of distribution of emojis used on Twitter around the world [31]. The aforementioned study indicated that South-Eastern Asia and South America had the highest, while the USA and Japan had the lowest rates of using emojis on Twitter. It has also been possible to detect the emojis used most often by various countries; based on the results of this study, developed countries used less face emojis than developing countries. It was further concluded that emojis could reflect the living conditions of different counties around the world using correlation 
analyses between emoji distribution and world development indicators including life expectancy, tax rate, trade, and gross domestic product per capita. According to another study by Kim et al. [32], policy makers should benefit from online information including emoticons along with proven scientific data, since these symbols can represent public feelings like frustration about an infectious disease such as H1N1. Emoticons and Internet slang were also targeted in the process of extracting emotional contents from social media regarding public reaction to the outbreak of Middle East respiratory syndrome in Korea in 2015 [33]. Pointing out the impact of an infectious disease outbreak on public emotions, it was suggested that understanding interactions between a disease, mass media and public emotions might be effective to avoid from excessive fear and overreactions to infectious diseases. Conceivably, by using digital surveillance with the Internet, disease outbreaks could be detected earlier in every part of the world, providing an opportunity to react more quickly $[34,35]$.

A number of emojis have been created that could be related to infectious diseases. In 2017, the "mosquito" (W) emoji was proposed with the objective to improve communication and research regarding mosquito-borne diseases and to monitor mosquito-borne disease outbreaks [36]. "Face with thermometer" (-0) and "sneezing face" (3) are among the smileys that may be used to represent a hospital patient, person with a cold or flu or other physical diseases. New health-related emojis in other categories including "lab coat" ("), "microbe" (1). "test tube" ( ), "petri dish" ( have also been added as part of Unicode 11.0 in 2018 to facilitate scientific communication in the digital world.

Considering the significant role of person-to-person transmission of infectious diseases and the necessity of behavioral adherence to IPC interventions, behavioral science is directly associated with infectious disease models [37]. Therefore, the existing set of emojis may be useful for showing behaviors associated with IPC such as hand hygiene. Bearing in mind the limited number of health-related emojis, positive effects of the currently available symbols in the field of IPC are questionable.

\section{The example of hand hygiene}

Healthcare-associated infections are considered a threat to patient safety [38]. Hand hygiene with alcohol-based hand rub, which is the global standard of care, is recognized as the cornerstone of IPC for preventing healthcare-associated infections [39]. Although hand hygiene is a very simple procedure, adherence levels are still worrisome and improving this behavior has been challenging despite using numerous interventions [40,
41]. The core components of the WHO multimodal hand hygiene improvement strategy include system change, education, evaluation and feedback, reminders in the workplace, and institutional safety climate [42]. In order to overcome behavioral barriers multiple interventions have been performed. Emojis may be beneficial in bridging the large gap that exists between the verbal text-based and nonverbal face-to-face interactions related to hand hygiene and the multimodal promotion approach. Thereby, employing them to improve hand hygiene behavior in accordance with the multimodal strategy deserves much more attention.

Education entertainment provided by social media is a promising method to promote individual behavior change such as hand hygiene [43], and emojis are helpful tools to add topics and ideas by facilitating a more natural communication [6]. According to the literature, visual stimuli have been found effective to use in lectures and written texts in order to improve hand hygiene behavior and it has also been suggested that animated visual elements may have a better and more direct effect compared with static pictures [44-46]. Likewise, emotional events are memorized more precisely and for a longer duration compared with neutral events, making them beneficial aspects to consider in education and memory [47]. In line with the possible advantages mentioned for these symbols, the first pilot intervention to assess the impact of emoticons on hand hygiene was performed by Gaube et al. in a German hospital [48]. Monitoring and feedback devices were installed above handrub dispensers that displayed a frowny face to remind people to perform hand hygiene and, once used, a smiley face was shown to reinforce the positive behavior. Based on their findings, emoticons can enhance hand hygiene in hospitals by providing visual cues and preventing forgetfulness concerning when it needs to be performed. Furthermore, emoticons could reinforce the hand hygiene behavior by providing instant feedback in patients' rooms.

Other studies have pointed to the importance of improving the use of social media platforms by IPC professionals in order to leverage the latest technologies in conveying hand hygiene messages $[43,49,50]$. This was further illustrated in a study conducted in China, which suggested that hand hygiene promotion strategies could be assessed using information obtained from social media, augmenting the data provided by traditional sources such as radio, print, and television [51]. According to the study performed by Pan et al. [50], a hand hygiene campaign video was more effectively connected through Facebook than through a group email and hospital website in Taiwan. It was also recommended that utilization of social media improves hand hygiene programs by 
providing a safe environment that enables public awareness and includes patient participation. The aforementioned results are consistent with previously performed studies describing the emotional content that is available on Facebook, Twitter, and other social media sites as "contagious" [52, 53]. Therefore, health-related interventions could also be influenced by the emotional cascade effect from one person to others, leading to improved efficacy and increased costeffectiveness of medical interventions [53]. A preponderance of evidence suggests that it seems beneficial to study the impact of emojis as an inseparable language of the digital platform on the emotional contagion and subsequent behavioral changes regarding hand hygiene.

A wide variety of other new strategies for the use of emojis could be suggested to improve hand hygiene. A qualitative study was performed in Australia to evaluate hand hygiene compliance among hospital cleaners [54]. Despite being aware of the necessity of hand hygiene, adherence levels were still very low in this group. Their results indicated that hand hygiene information overload and confusing training material and programs were barriers to hand hygiene promotion. Using simplified reminders such as posters with comprehensive language may be more beneficial and less time consuming compared with the detailed materials used for training hospital cleaning staff. Another advantage of using emojis in hand hygiene could be the possibility of introducing universal emoji translation of the WHO "My five moments for hand hygiene" $[55,56]$ with precisely selected emojis in order to prevent misinterpretations by different individuals.

\section{Current state and future prospects}

Hand hygiene-related terms have been transformed over the past years from handwashing and hand disinfection to hand hygiene, underlining the increased performance and use of alcohol-based handrub compared to soap and water, and the prominence of this topic in patient safety $[56,57]$. There are currently 30 different hand gesture emojis available, however there is no emoji directly showing hand washing, handrubbing or handrub (Fig. 1). The act of cleaning hands could be only demonstrated using a sequence of any of the existing hand emojis with the "bar of soap" (-) emoji, which makes communication more complicated than using a single emoji. For example, some people may interpret the combination of the "clapping hands" and "bar of soap" ( as applauding the use of soap and it may not directly demonstrate hand washing with soap. The development of hand hygiene-related emojis will enable health professionals to communicate more specifically regarding their discoveries and concerns in this field. In addition, the hand hygiene compliance of different places in the world could be better notified by detecting relevant emojis in the social media to predict compliance or even identify problems caused by low adherence. Hand hygienerelated emojis on social media could regularly remind us to protect ourselves against healthcare-associated infections, and the spread of influenza or antimicrobial resistance. More importantly, the general public, including patients suffering from healthcare-associated infections, might be able to easily share and communicate the problems they have faced, as they could be better heard

\begin{tabular}{|c|c|c|c|c|c|c|}
\hline & \&प & Waving Hand & be & \begin{tabular}{|l|} 
Love-You \\
Gesture
\end{tabular} & $t^{n+4}$ & $\begin{array}{l}\text { Raising } \\
\text { Hands }\end{array}$ \\
\hline & $\sqrt{14}$ & $\begin{array}{l}\text { Raised Back of } \\
\text { Hand }\end{array}$ & (c) & \begin{tabular}{|l} 
Sign of the \\
Horns
\end{tabular} & $\sqrt{3}$ & Thumbs Up \\
\hline & Wh & $\begin{array}{l}\text { Hand with } \\
\text { Fingers Splayed }\end{array}$ & $\sqrt{3}$ & Call Me Hand & ge & $\begin{array}{l}\text { Thumbs } \\
\text { Down }\end{array}$ \\
\hline & 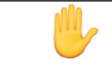 & Raised Hand & 2 & \begin{tabular}{|l|} 
Backhand Index \\
Pointing Left
\end{tabular} & 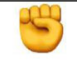 & Raised Fist \\
\hline & (1) & Vulcan Salute & $\sigma$ & $\begin{array}{l}\text { Backhand Index } \\
\text { Pointing Right }\end{array}$ & a1] & $\begin{array}{l}\text { Oncoming } \\
\text { Fist }\end{array}$ \\
\hline & d) & OK Hand & 8 & $\begin{array}{l}\text { Backhand Index } \\
\text { Pointing Up }\end{array}$ & $Q$ & $\begin{array}{l}\text { Left-Facing } \\
\text { Fist }\end{array}$ \\
\hline & 8 & Victory Hand & G & $\begin{array}{l}\text { Backhand Index } \\
\text { Pointing Down }\end{array}$ & $2 \pi$ & $\begin{array}{l}\text { Right-Facing } \\
\text { Fist }\end{array}$ \\
\hline & 6 & Crossed Fingers & ed & $\begin{array}{l}\text { Index Pointing } \\
\text { Up }\end{array}$ & (4) & $\begin{array}{l}\text { Clapping } \\
\text { Hands }\end{array}$ \\
\hline & 1 & Writing Hand & $\pi$ & Middle Finger & (itill) & $\begin{array}{l}\text { Palms Up } \\
\text { Together }\end{array}$ \\
\hline & a & Folded Hands & tye & Open Hands & 9 & Handshake \\
\hline
\end{tabular}


globally and have the possibility of sharing their feelings using different emojis.

\section{Conclusion}

Emojis may empower IPC in different aspects such as raising awareness with no language barrier, educating people to adopt healthy behaviors, and enhancing surveillance systems to monitor infectious diseases. It is recommended to evaluate the relevance and appropriateness of the current set of emojis to use for hand hygiene promotion in order to harness the potential beneficial impact of these symbols. Medical emojis that are standardized as a new category of emojis offer much hope for the future, especially in the field of IPC.

\section{Acknowledgements}

Didier Pittet works with WHO in the context of the WHO initiative 'Private Organizations for Patient Safety - Hand Hygiene'. The aim of this WHO initiative is to harness industry strengths to align and improve implementation of $\mathrm{WHO}$ recommendations for hand hygiene in health care indifferent parts of the world, including in least developed countries. In this instance, companies/industry with a focus on hand hygiene and infection control related advancement have the specific aim of improving access to affordable hand hygiene products as well as through education and research. All listed authors declare no financial support, grants, financial interests or consultancy that could lead to conflicts of interest.

The authors alone are responsible for the views expressed in this article and they do not necessarily represent the views, decisions or policies of the institutions with which they are affiliated. WHO takes no responsibility for the information provided or the views expressed in this paper.

\section{Authors' contributions}

NL drafted the manuscript with the help of RA and MA. DP critically revised and supervised the study. All authors read and approved the final manuscript.

\section{Funding}

This work is supported by the Infection Control Programme and World Health Organization (WHO) Collaborating Centre on Patient Safety (SPCl) W(C), University of Geneva Hospitals and Faculty of Medicine, Geneva, Switzerland; hand hygiene research activities at the SPCIMCC are also supported by the Swiss National Science Foundation (grant no. 32003B_163262)

\section{Availability of data and materials}

Data sharing not applicable to this article as no datasets were generated or analyzed during the current study.

\section{Ethics approval and consent to participate}

Not applicable.

\section{Consent for publication}

Not applicable.

\section{Competing interests}

The authors declare that they have no competing interests.

\section{Author details}

${ }^{1}$ Department of Research, Faculty of Medicine, Mashhad University of Medical Sciences, Mashhad, Iran. ${ }^{2}$ Hand Hygiene and Infection Control Research Center, Imam Reza Hospital, Mashhad, Iran. ${ }^{3}$ E-Learning Center, School of Medicine, Mashhad University of Medical Sciences, Mashhad, Iran. ${ }^{4}$ Department of Pediatrics \& Hand Hygiene and Infection Control Research Center, Imam Reza Hospital, Mashhad, Iran. ${ }^{5}$ Infection Control Programme and WHO Collaborating Centre on Patient Safety, University of Geneva Hospitals and Faculty of Medicine, 4 Rue Gabrielle-Perret-Gentil, 1211 Geneva 14, Switzerland.
Received: 26 November 2019 Accepted: 3 February 2020

Published online: 10 February 2020

\section{References}

1. Kralj Novak P, Smailović J, Sluban B, Mozetič I. Sentiment of emojis. PLoS One. 2015;10(12):e0144296.

2. Kaye LK, Malone SA, Wall HJ. Emojis: insights, affordances, and possibilities for psychological science. Trends Cogn Sci. 2017;21(2):66-8.

3. Walther JB, D'Addario KP. The impacts of emoticons on message interpretation in computer-mediated communication. Soc Sci Comput Rev. 2001;19(3):324-47.

4. Yuasa M, Saito K, Mukawa N. Brain activity when reading sentences and emoticons: an fMRI study of verbal and nonverbal communication. Electron Commun Jpn. 2011;94(5):17-24.

5. O'Reilly-Shah V, Lynde G, Jabaley C. Is it time to start using the emoji in biomedical literature? BMJ. 2018;363:k5033.

6. Lu X, Ai W, Liu X, Li Q, Wang N, Huang G, et al. Learning from the ubiquitous language: an empirical analysis of emoji usage of smartphone users. Proceedings of the 2016 ACM International Joint Conference on Pervasive and Ubiquitous Computing; Heidelberg, Germany. 2971724: ACM; 2016. p. $770-80$

7. Oxford Dictionaries. Word of the Year 2015. https://en.oxforddictionaries. com/word-of-the-year/word-of-the-year-2015. Accessed 1 Feb 2020.

8. Troiano G, Nante N. Emoji: what does the scientific literature say about them?-a new way to communicate in the 21th century. J Hum Behav Soc Environ. 2018;28(4):528-33.

9. Bedoya G, Dolinger A, Rogo K, Mwaura N, Wafula F, Coarasa J, et al. Observations of infection prevention and control practices in primary health care, Kenya. Bull World Health Organ. 2017;95(7):503-16.

10. Wulff HR. The language of medicine. J R Soc Med. 2004;97(4):187-8.

11. Amano T, González-Varo JP, Sutherland WJ. Languages are still a major barrier to global science. PLoS Biol. 2016;14(12):e2000933.

12. Murray S, Skull S. Hurdles to health: immigrant and refugee health care in Australia. Australian health review: a publication of the Australian Hospital Association. 2005;29:25-9.

13. Ali PA, Watson R. Language barriers and their impact on provision of care to patients with limited English proficiency: nurses' perspectives. J Clin Nurs. 2018;27(5-6):e1152-e60.

14. Aronson J. Medical emoticons. BMJ. 2005;330(7482):87.

15. Lo S-K. The nonverbal communication functions of emoticons in computermediated communication. Cyberpsychol Behav. 2008;11:595-7.

16. Willoughby JF, Liu S. Do pictures help tell the story? An experimental test of narrative and emojis in a health text message intervention. Comput Hum Behav. 2018;79:75-82.

17. Siegel R, Anneken A, Duffy C, Simmons K, Hudgens M, Shelly J. Emoticon use increases plain milk and vegetable purchase in a school cafeteria without adversely affecting total milk purchase. Clin Ther. 2015;37:1938-43.

18. Lee ACK, Tang SW, Yu GKK, Cheung RTF. The smiley as a simple screening tool for depression after stroke: a preliminary study. Int J Nurs Stud. 2008; 45(7):1081-9.

19. Marengo D, Giannotta F, Settanni M. Assessing personality using emoji: an exploratory study. Personal Individ Differ. 2017;112:74-8.

20. Weiß M, Gutzeit J, Rodrigues J, Mussel P, Hewig J. Do emojis influence social interactions? Neural and behavioral responses to affective emojis in bargaining situations. Psychophysiology. 2019;56(4):e13321.

21. Aldunate N, Villena-González M, Rojas-Thomas F, López V, Bosman CA. Mood detection in ambiguous messages: the interaction between text and emoticons. Front Psychol. 2018;9:423.

22. Butterworth SE, Giuliano TA, White J, Cantu L, Fraser KC. Sender gender influences emoji interpretation in text messages. Front Psychol. 2019;10: 784.

23. Filik R, Turcan A, Thompson D, Harvey N, Davies H, Turner A. Sarcasm and emoticons: comprehension and emotional impact. Q J Exp Psychol. 2016; 69(11):2130-46

24. Fernández-Luque $L$, Bau T. Health and social media: perfect storm of information. Healthc Inform Res. 2015;21(2):67-73.

25. Kummervold PE, Chronaki CE, Lausen B, Prokosch H-U, Rasmussen J, Santana S, et al. eHealth trends in Europe 2005-2007: a population-based survey. J Med Internet Res. 2008;10(4):e42.

26. Skiba DJ. Face with tears of joy is word of the year: are emoji a sign of things to come in health care? Nurs Educ Perspect. 2016;37(1):56-7. 
27. Assadi R. Medical emoji a new paradigm for virtual medical counseling. https://www.bmj.com/content/363/bmj.k5033/rr-5. Accessed 25 Oct 2019.

28. Allegranzi B, Kilpatrick C, Storr J, Kelley E, Park BJ, Donaldson L, et al. Global infection prevention and control priorities 2018-22: a call for action. Lancet Glob Health. 2017;5(12):e1178-e80.

29. Kass-Hout TA, Alhinnawi H. Social media in public health. Br Med Bull. 2013; 108(1):5-24.

30. Fung IC-H, Tse ZTH, Fu K-W. The use of social media in public health surveillance. Western Pac Surveill Response J. 2015;6(2):3-6.

31. Ljubešić N, Fišer D, editors. A global analysis of emoji usage: Proceedings of the 10th Web as Corpus Workshop. Berlin: Association for Computational Linguistics; 2016.

32. Kim S, Pinkerton T, Ganesh N. Assessment of H1N1 questions and answers posted on the web. Am J Infect Control. 2012;40(3):211-7.

33. Choi S, Lee J, Kang M-G, Min H, Chang Y-S, Yoon S. Large-scale machine learning of media outlets for understanding public reactions to nation-wide viral infection outbreaks. Methods. 2017:129:50-9.

34. Seo D-W, Shin S-Y. Methods using social media and search queries to predict infectious disease outbreaks. Healthc Inform Res. 2017;23(4):343-8.

35. Charles-Smith LE, Reynolds TL, Cameron MA, Conway M, Lau EHY, Olsen JM, et al. Using social media for actionable disease surveillance and outbreak management: a systematic literature review. PLoS One. 2015;10(10): e0139701.

36. Chertack J, Shaivitz M. Proposal for mosquito emoji. http://www.unicode. org/L2/L2017/17268-mosquito-emoji.pdf. Accessed 25 Oct 2019.

37. Weston D, Hauck K, Amlôt R. Infection prevention behaviour and infectious disease modelling: a review of the literature and recommendations for the future. BMC Public Health. 2018;18(1):336.

38. Pittet $D$, Donaldson L. Clean care is safer care: a worldwide priority. Lancet. 2005;366:1246-7.

39. Vermeil T, Peters A, Kilpatrick C, Pires D, Allegranzi B, Pittet D. Hand hygiene in hospitals: anatomy of a revolution. J Hosp Infect. 2019;101(4):383-92.

40. Gould DJ, Drey N, Moralejo D, Grimshaw J, Chudleigh J. Interventions to improve hand hygiene compliance in patient care. J Hosp Infect. 2008;68: 193-202.

41. Pittet D. Hand hygiene: from research to action. J Infect Prev. 2017;18(3): 100-2.

42. World Health Organization. Guide to implementation: a guide to the implementation of the WHO Multimodal Hand Hygiene Improvement Strategy. http://www.who.int/gpsc/5may/Guide_to_Implementation.pdf. Accessed 21 Oct 2019.

43. Lim K, Kilpatrick C, Storr J, Seale H. Exploring the use of entertainmenteducation YouTube videos focused on infection prevention and control. Am J Infect Control. 2018:46(11):1218-23.

44. Beyfus T, Dawson N, Danner C, Rawal B, Gruber P, Petrou S. The use of passive visual stimuli to enhance compliance with handwashing in a perioperative setting. Am J Infect Control. 2016;44:496-9.

45. Stella S, Stace R, Knepper B, Reese S, Keniston A, Burden M, et al. The effect of eye images and a social norms message on healthcare provider hand hygiene adherence. Infect Control Hosp Epidemiol. 2019;40:1-7.

46. Bobek E, Tversky B. Creating visual explanations improves learning. Cogn Res Princ Implic. 2016;1(1):27.

47. Tyng CM, Amin HU, Saad MNM, Malik AS. The influences of emotion on learning and memory. Front Psychol. 2017;8:1454.

48. Gaube S, Tsivrikos D, Dollinger D, Lermer E. How a smiley protects health: a pilot intervention to improve hand hygiene in hospitals by activating injunctive norms through emoticons. PLoS One. 2018;13(5):e0197465.

49. Jenner EA, Jones F, Fletcher B, Miller L, Scott GM. Hand hygiene posters: motivators or mixed messages? J Hosp Infect. 2005;60:218-25.

50. Pan S-C, Sheng W-H, Kuei Lien T, Chien K-T, Chen Y-C, Chang S-C. Promoting a hand hygiene program using social media: an observational study. JMIR Public Health Surveill. 2016;2:e5.

51. Fung IC-H, Cai J, Hao Y, Ying Y, Chan BSB, Tse ZTH, et al. Global Handwashing day 2012: a qualitative content analysis of Chinese social media reaction to a health promotion event. Western Pac Surveill Response J. 2015;6(3):34-42.

52. Gruzd A, Doiron S, Mai P. Is happiness contagious online? A case of Twitter and the 2010 Winter Olympics. 2011 44th Hawaii International Conference on System Sciences; 2011 4-7 Jan. 2011
53. Coviello L, Sohn Y, Kramer ADI, Marlow C, Franceschetti M, Christakis NA, et al. Detecting emotional contagion in massive social networks. PLoS One. 2014;9(3):e90315.

54. Sendall MC, McCosker LK, Halton K. Cleaning staff's attitudes about hand hygiene in a metropolitan hospital in Australia: a qualitative study. Int J Environ Res Public Health. 2019;16(6):1067.

55. Sax H, Allegranzi B, Uçkay I, Larson E, Boyce J, Pittet D. 'My five moments for hand hygiene': a user-centred design approach to understand, train, monitor and report hand hygiene. J Hosp Infect. 2007;67(1):9-21.

56. World Health Organization. Guidelines on hand hygiene in health care. First global patient safety challenge clean care is safer care. https://apps.who.int/ iris/bitstream/handle/10665/44102/9789241597906_eng.pdf?sequence=1. Accessed 21 Oct 2019.

57. Pires D, Tartari E, Bellissimo-Rodrigues F, Pittet D. Why language matters: a tour through hand hygiene literature. Antimicrob Resist Infect Control. 2017; 6:65.

\section{Publisher's Note}

Springer Nature remains neutral with regard to jurisdictional claims in published maps and institutional affiliations.
Ready to submit your research? Choose BMC and benefit from:

- fast, convenient online submission

- thorough peer review by experienced researchers in your field

- rapid publication on acceptance

- support for research data, including large and complex data types

- gold Open Access which fosters wider collaboration and increased citations

- maximum visibility for your research: over $100 \mathrm{M}$ website views per year

At BMC, research is always in progress.

Learn more biomedcentral.com/submissions 